\title{
Thermolysis of some $\mathbf{N}$-arylbenzamidoximes: Mechanistic studies for formation of anilide, oxazole and imidazole derivatives
}

\author{
ABDEL-AAL GABER ${ }^{\mathrm{a}, * \text { (D) } \text { and LAYLA TAIB }}{ }^{\mathrm{b}}$ \\ ${ }^{a}$ Chemistry Department, Faculty of Science, Assiut University, Assiut 71516, Egypt \\ ${ }^{\mathrm{b}}$ Chemistry Department, Faculty of Science, King Abdulaziz University, Jeddah 21589, Saudi Arabia \\ e-mail: amabdelaal@hotmail.com; laylataib@yahoo.com
}

MS received 16 December 2015; revised 17 February 2016; accepted 25 February 2016

\begin{abstract}
The thermolysis of N-2-pyridylbenzamidoxime I under nitrogen atmosphere for 5 hours gives rise to 2-phenyl- $1 H$-imidazo[4,5-b]pyridine and $\mathrm{N}$-(pyridin-2-yl)benzamide as the major products $(52.4$ and $18.11 \%$, respectively), in addition to 2-hydroxy pyridine, benzonitrile, benzoic acid, 2-aminopyridine, 2-phenyloxazolo[4,5-b]pyridine, 9H-pyrrolo[2,3-b:5,4-b']dipyridine and 2,4,6-triphenyl-1,3,5-triazine. Also, heating $\mathrm{N}$ - $\alpha$-naphthylbenzamidoxime II under the same conditions gave $\mathrm{N}-(\alpha$-Naphthyl)benzamide, 2-Phenyl$3 H$-naphtho[2,1-d] imidazole as the major products besides benzonitrile, benzoic acid, $\alpha$-naphthylamine and 2-phenylnaphtho[1,2-d]oxazole. In the presence of tetralin, I gave 1-hydroxytetralin, $\alpha$-tetralone and 1,1'bitetrayl besides the previous products. The reaction and isolated products have been interpreted in terms of a free radical mechanism involving the homolysis of $\mathrm{N}-\mathrm{O}$ and/or $\mathrm{C}-\mathrm{N}$ bonds.
\end{abstract}

Keywords. Thermolysis; rearrangement; $N$-2-pyridyl- and $N$ - $\alpha$-Naphthylbenz- amidoxime; imidazo- and oxazolo derivatives.

\section{Introduction}

As an important organic family, amidoximes, in general are useful precursors for the synthesis of versatile heterocyclic compounds such as oxazoles, imidazoles, oxadiazoles, tetrazoles, etc. ${ }^{1-4}$ Also, we have reported that flash vacuum pyrolysis (FVP) of the benzamide oximes leads to the formation of the imino-oxadiazole as the major product and suggested to be formed by intermolecular cycloaddition of benzonitrile oxide the diphenylcarbodiimide. ${ }^{5}$ Moreover, thermal fragmentation and rearrangement of $\mathrm{N}$-arylbenzamidoximes gave benzimi dazoles, anilides, aryl amines, phenols and 2-phenylbenzoxazole. ${ }^{6,7}$ Also, thermolysis of $\mathrm{N}$-arylnicotin- amide oximes under nitrogen atmosphere gave rise to benzimidazoles and anilides as major products in addition to arylamines, nicotinic acid, phenols and 2-(pyridine-3-yl) benzoxazoles. ${ }^{8}$ Recently, Gaber et al., ${ }^{9}$ have reported that the photolysis of some $\mathrm{N}$-arylbenzamidoxime derivatives in dry acetonitrile gives rise to anilides and benzimidazoles as the major products in addition to benzonitrile, arylamines, benzoic acid, and 2-phenyl benzoxazoles. Several papers have been published on the use of amidoximes as antibacterial, ${ }^{10}$ trypanocide $^{11}$ and as functional group which can serve as prodrug for the amidoxime group. ${ }^{12}$ The biological importance

\footnotetext{
*For correspondence
}

of amidoxime derivatives has prompted us to reinvestigate the thermolysis of these compounds in order to gain further insight into the mechanistic pathways of fragmentation.

\section{Experimental}

\subsection{General Methods}

All melting points were measured with a Gallen kamp apparatus and are uncorrected. The IR spectra were recorded on a Shimadzu IR-470 spectrophotometer. All thermolysis experiments were carried out in high purity HPLC grade acetonitrile purchased from Sigma Aldrich. The thermolysis progressing and the purity of the isolated products were monitored using thin layer chromatography (TLC) and the progress was followed using thin layer chromatography on aluminum sheets covered with silica gel with layer thickness of $0.2 \mathrm{~mm}$ and acetonepetroleum-ether $\left(60-80^{\circ} \mathrm{C}\right)(1: 4 \mathrm{v} / \mathrm{v})$. Purification and separation of the products were done using column chromatography using a glass column $(120 \times 2.5 \mathrm{~cm})$ packed with Kieselgel $60(0.040-0.063 \mathrm{~mm})$ using light petroleum-ether and ether-pentane with different ratios (1 and 2\%). Gas-liquid chromatography was carried out on a Perkin-Elmer, model Sigma 3B apparatus, using a $4 \mathrm{ft} \times 4 \mathrm{~mm}$ column packed with SE 30 over Chromosorb W (35-80 mesh) or 10\% SE 30 on Celite 
(60-80 mesh) at $200^{\circ} \mathrm{C}$, using nitrogen as a carrier gas. ${ }^{1} \mathrm{H}$ and ${ }^{13} \mathrm{C}$-NMR spectra for the starting materials and some reaction products were recorded using Varian EM 600 and $150 \mathrm{MHz}$ instrument, respectively. The isolated products were separated and analyzed by IR, GLC, TLC, elemental analysis, ${ }^{1} \mathrm{H}$ and ${ }^{13} \mathrm{C}-\mathrm{NMR}$, and GC/MS and compared with authentic samples.

\subsection{Starting materials}

$\mathrm{N}$-(Pyridin-2-yl)benzamidoxime I was prepared through mixture of 2-Amino pyridine $(9.98 \mathrm{~mL}$, 0.1 mole), benzonitrile $(9.98 \mathrm{~mL}, 0.1$ mole), and granular sodium $(2.3 \mathrm{~g}, 0.1$ mole $)$ in dry benzene $(100 \mathrm{~mL})$ was refluxed for 27 consecutive hours. After addition of ethanol $(10 \mathrm{~mL})$, ionizable cyanide was extracted with dilute sodium hydroxide and recovered as silver cyanide $(0.73 \mathrm{~g}, 5.5 \%)$. Basic material was then collected in dilute hydrochloric acid and $N$-(pyridin-2-yl) benzamidine was precipitated by sodium hydroxide. $N$-(Pyridin-2-yl)benzamidine (19.72 g, 0.1 mole) was added to a solution of hydroxylamine hydrochloride (10.4 g, 1.5 mole) in water $(90 \mathrm{~mL})$. The suspension was boiled for $10 \mathrm{~min}$, made just alkaline to brilliant-yellow solution with ammonia, and boiled for a further $10 \mathrm{~min}$. The solid separated furnished the pure amidoxime, as pale yellow crystals, M.p. $186-188^{\circ} \mathrm{C}$, upon recrystallization from ethanol; yield $46.65 \%, \mathrm{R}_{f}=0.221$ (acetone: petroleum ether $\left.\left(60-80^{\circ} \mathrm{C}\right), 3: 7 \mathrm{v} / \mathrm{v}\right)$; (lit; ${ }^{13}$ mp 185-7 $\left.{ }^{\circ} \mathrm{C}\right)$; IR $\left(\mathrm{KBr}, \mathrm{cm}^{-1}\right): 3476(\mathrm{OH}), 3364(\mathrm{NH})$, 3110 ( $\mathrm{CH}$ aromatic), $1641(\mathrm{C}=\mathrm{C}$ aromatic), 1335 (C-N), 1256 (C-O). ${ }^{1} \mathrm{H}-\mathrm{NMR}\left(600 \mathrm{MHz}, \mathrm{DMSO}-\mathrm{d}_{6}\right) \delta$ : 10.88 (s, 1H, OH), 8.71 (s, 1H, NH), 7.91 (d, 1H, $J=$ 4.8), 7.52 (t, 1H), 7.39 (dd, $1 \mathrm{H}, J=4.2,1.2), 7.33$ $(\mathrm{m}, 5 \mathrm{H}, \mathrm{Ph}-\mathrm{H}), 6.74(\mathrm{~m}, 1 \mathrm{H}) ;{ }^{13} \mathrm{C}-\mathrm{NMR}(150 \mathrm{MHz}$, DMSO-d $\left._{6}\right) \delta: 206.7(\mathrm{C}=\mathrm{NOH}), 154.06(\mathrm{C}-\mathrm{Py}), 147.26$ (CH-Py), 137.27 (CH-Py),133.72(C-Ph), 128.6 (CH$\mathrm{Ph}$ ), 128 (2CH-Py), 126.9 (2CH-Ph), 115.7 (CH-Py), 111.9 (CH-Py); MS (EI, $\left.150^{\circ} \mathrm{C}\right), \mathrm{m} / \mathrm{e}(\%): 213\left(\mathrm{M}^{+}\right.$, 35.29), 196 (13.23), 181 (31.61), 94 (36.76), 79 (27.9), 77 (100), 51 (12.92); elemental analysis calculated for $\mathrm{C}_{12} \mathrm{H}_{11} \mathrm{~N}_{3} \mathrm{O}: \mathrm{C}, 67.59 ; \mathrm{H}, 5.20 ; \mathrm{N}, 19.71 \%$. Found: C, 67.26; H, 5.53; N, 20.20\%.

$\mathrm{N}-\alpha$-Naphthylbenzamidoxime II was prepared by the same procedure through a mixture of $\alpha$-naphthylamine (14.31 g, 0.1 mole), benzonitrile $(9.98 \mathrm{~mL}, 0.1 \mathrm{~mole})$, and granular sodium $(2.3 \mathrm{~g}, 0.1$ mole $)$ in dry benzene $(100 \mathrm{~mL})$ was refluxed for 27 consecutive hours. After addition of ethanol $(10 \mathrm{~mL})$, ionizable cyanide was extracted with dilute sodium hydroxide and recovered as silver cyanide $(0.73 \mathrm{~g}, 5.5 \%)$. Basic material was then collected in dilute hydrochloric acid and $N$ - $\alpha$-naphthylbenzamidine was precipitated by sodium hydroxide. $N$ - $\alpha$-Naphthylbenzamidine ( $24.6 \mathrm{~g}, 0.1 \mathrm{~mole}$ ) was added to a solution of hydroxyl amine hydrochloride (10.4 g, $1.5 \mathrm{~mole})$ in water $(90 \mathrm{~mL})$. The suspension was boiled for $10 \mathrm{~min}$, made just alkaline with ammonia, and boiled for a further $10 \mathrm{~min}$. The residue was treated with pet.ether $\left(60-80^{\circ} \mathrm{C}\right)$. The solid separated furnished the pure amidoxime, as dark purple crystals upon recrystallization from benzene, M.p. $184-186^{\circ} \mathrm{C}$; yield 30.29\%; $\mathrm{R}_{f}=0.285$ (acetone: petroleum ether $\left.\left(60-80^{\circ} \mathrm{C}\right) 3: 7 \mathrm{v} / \mathrm{v}\right)$; (lit; $\left.{ }^{13} \mathrm{mp} 181-3^{\circ} \mathrm{C}\right)$; IR ( $\mathrm{KBr}$, $\left.\mathrm{cm}^{-1}\right): 3382(\mathrm{OH}), 3361(\mathrm{NH}), 3058(\mathrm{CH}$ aromatic), $1642\left(\mathrm{C}=\mathrm{C}\right.$ aromatic), $1363(\mathrm{C}-\mathrm{N}), 1245(\mathrm{C}-\mathrm{O}) ;{ }^{1} \mathrm{H}-$ NMR $\left(600 \mathrm{MHz}, \mathrm{DMSO}_{-} \mathrm{d}_{6}\right) \delta: 10.66(\mathrm{~s}, 1 \mathrm{H}, \mathrm{OH})$, $8.34(\mathrm{~d}, 1 \mathrm{H}, J=8.4), 8.167(\mathrm{~s}, 1 \mathrm{H}, \mathrm{NH}), 7.87$ $(\mathrm{d}, 2 \mathrm{H}, J=8.4), 7.55$ (m, 2H), 7.34 (dd, 2H, $J=6,6.6)$ $7.22(\mathrm{~m}, 4 \mathrm{H}), 6.56(\mathrm{~d}, 1 \mathrm{H}, J=7.2) ;{ }^{13} \mathrm{C}-\mathrm{NMR}$ $\left(150 \mathrm{MHz}, \mathrm{CDCl}_{3}\right) \delta: 152.2(\mathrm{C}=\mathrm{NOH}), 135.7(\mathrm{C}-$ naph), 133.9 (C-Ph.), 131.6 (C-Ph), 128.9 (CH-Ph), 128.1 (CH-naph), 127.9 (2CH-Ph), 127.65 (C-naph), 127.60 (2CH-Ph), 125.9 (CH-naph), 125.8 (CH-naph), 125.0 (CH-naph), 123.17 (CH-naph), 121.6 (CH-naph), 119.84 (CH-naph); MS (EI, $\left.150^{\circ} \mathrm{C}\right), \mathrm{m} / \mathrm{e}(\%): 262\left(\mathrm{M}^{+}\right.$, 28.35), 246 (26.86), 245 (100), 230 (15), 143 (59.7), 127 (23.88), 115 (70.14), 77 (35.82), 51 (10.44); elemental analysis calculated for $\mathrm{C}_{17} \mathrm{H}_{14} \mathrm{~N}_{2} \mathrm{O}: \mathrm{C}, 77.84 ; \mathrm{H}$, 5.3; N, 10.68\%. Found: C, 78.04; H, 5.09; N, 10.27\%.

It is worth mentioning that a number of preliminary experiments were carried out to determine the proper temperature for thermolysis. The decomposition of $\mathbf{I}$ and II starts above $220^{\circ} \mathrm{C}$. Also, it was found that $250^{\circ} \mathrm{C}$ is the lowest temperature at which the conversion of $N$ arylbenzamidoximes I and II was complete at the end of thermolysis.

\subsection{Thermal fragmentation of $\mathrm{N}$-2-pyridylbenzamidoxime I}

General procedure: The appropriate N-2-pyridylbenzamidoxime I ( $1 \mathrm{~g})$ was heated under nitrogen stream at $220-250^{\circ} \mathrm{C}$ for $5 \mathrm{~h}$ using a temperature-controlled heating mantle adjusted to the required temperature. The temperature was measured using a thermometer immersed in the reaction flask. The gases evolved were detected by standard chemical methods $\left(\mathrm{NH}_{3}\right.$ by Nessler's reagent). After decomposition was complete, as judged by TLC monitoring, the products were separated into neutral, acidic, phenolic and basic components as in the previous work. ${ }^{14}$ The pyrolysate was dissolved in ether and shaken several times with ethanolic potassium hydroxide solution (Claisen's solution) to dissolve the resulting phenols. The Claisen extract was acidified with $2 \mathrm{M} \mathrm{HCl}$ and the liberated phenols were extracted with ether. Ether was evaporated in vacuo. 
Phenols and compounds were separated into its constituents by fractional distillation under reduced pressure, whereupon the following compounds were obtained: 2Hydroxypyridine 3, collected at B.p. $220-228^{\circ} \mathrm{C} / 6$ Torr; M.p. ${ }^{105}-107^{\circ} \mathrm{C}$. Benzoic acid 2 was identified by preparative TLC with authentic sample using petroleum ether $\left(60-80^{\circ} \mathrm{C}\right)$ - acetone $(5: 1 \mathrm{v} / \mathrm{v}), \mathrm{R}_{\mathrm{f}} 0.65$, and M.p. and mixed M.p. $121^{\circ} \mathrm{C}$. Benzonitrile 1, collected at B.p. $41-5^{\circ} \mathrm{C} / 3$ torr; on hydrolysis gave benzoic acid 2, M.p. and mixed M.p. $121^{\circ} \mathrm{C}$. Amino compounds were separated into its constituents by fractional distillation under reduced pressure such as 2 -amino pyridine 4 , collected at B.p. $180-188^{\circ} \mathrm{C} / 6$ Torr; M.p. $54-58^{\circ} \mathrm{C}$; IR is coincident with that of an authentic sample. The remaining residue (non-distillable) was separated by column chromatography on Kieselgel $60((0.040-0.063 \mathrm{~mm})$ as follows:

$\mathrm{N}$-(Pyridin-2-yl)benzamide 9 was eluted using petether $\left(60-80^{\circ} \mathrm{C}\right)$-benzene $(1: 1 \mathrm{v} / \mathrm{v})$ as eluent; M.p. $81-$ $83^{\circ} \mathrm{C}$ (lit., ${ }^{15}$ M.p. $\left(80-82^{\circ} \mathrm{C}\right) ; \mathrm{R}_{\mathrm{f}}=0.26$ (30:70 acetonehexane); IR $\left(\mathrm{KBr}, \mathrm{cm}^{-1}\right)$ : 3288, 3058, 1650, 1584, 1537, 1481, 1330; ${ }^{1} \mathrm{H}-\mathrm{NMR}\left(600 \mathrm{MHz}, \mathrm{CDCl}_{3}\right) \delta=$ $6.95(\mathrm{~m}, 1 \mathrm{H}), 7.41(\mathrm{~m}, 2 \mathrm{H}), 7.49(\mathrm{~m}, 1 \mathrm{H}), 7.68(\mathrm{~m}, 1 \mathrm{H})$, 7.88 (m, 2H), 9.39 (s, br, 1H), $8.01(\mathrm{~m}, 1 \mathrm{H}), 8.37$ (m, 1H); MS (EI, $\left.150^{\circ} \mathrm{C}\right), \mathrm{m} / \mathrm{e}(\%): 198$ (8), 169 (50), 105 (100), 77 (85), 51 (30).

2,4,6-Triphenyl-1,3,5-triazine 7 was eluted using petether $\left(60-80^{\circ} \mathrm{C}\right)$-benzene $(1: 2 \mathrm{v} / \mathrm{v})$ as eluent, in the form of light yellow needles, M.p. $231-233^{\circ} \mathrm{C}$ (lit., ${ }^{16}$ M.p. $\left.230-232^{\circ} \mathrm{C}\right) ; \mathrm{R}_{\mathrm{f}}=0.36(9: 1 \mathrm{v} / \mathrm{v}$ n-hexanedichloromethane); ${ }^{1} \mathrm{H}-\mathrm{NMR}\left(600 \mathrm{MHz}, \mathrm{CDCl}_{3}\right) \delta=$ $8.79(\mathrm{~d}, 6 \mathrm{H}, J=7.8 \mathrm{~Hz}), 7.61(\mathrm{~s}, 6 \mathrm{H}), 7.59(\mathrm{~s}, 3 \mathrm{H})$; MS (EI, $\left.150^{\circ} \mathrm{C}\right)$ ), m/e (\%): 309 (30), 103 (100), 76 (20), 51 (10); elemental analysis calculated for $\mathrm{C}_{21} \mathrm{H}_{15} \mathrm{~N}_{3}$ : C, 81.53; H, 4.89; N, 13.58\%. Found: C, 81.42; H, 4.77; $\mathrm{N}, 13.61 \%$.

$9 H$-pyrrolo[2,3-b:4,5-b']dipyridine $\mathbf{6}$ was eluted using pet-ether $\left(60-80^{\circ} \mathrm{C}\right)$-benzene $(1: 4 \mathrm{v} / \mathrm{v})$; M.p. 229-231 $1^{\circ} \mathrm{C}$ (lit., ${ }^{17}$ M.p. $230-232^{\circ} \mathrm{C}$ ); elemental analysis calculated for $\mathrm{C}_{10} \mathrm{H}_{7} \mathrm{~N}_{3}: \mathrm{C}, 70.95 ; \mathrm{H}, 4.15 ; \mathrm{N}$, 24.85\%. Found: C, 70.9; H, 4.15; N, 25.0\%. 2Phenyloxazolo[4,5-b]pyridine 5 was eluted using $1 \%$ ether-pentane, mp $125-127^{\circ} \mathrm{C}$ (lit., ${ }^{18}$ M.p. $127-128^{\circ} \mathrm{C}$; $\mathrm{R}_{\mathrm{f}}=0.56$ (ethylacetate - pentane, $\left.1: 2 \mathrm{v} / \mathrm{v}\right) ;{ }^{1} \mathrm{H}-\mathrm{NMR}$ $\left(600 \mathrm{MHz}, \mathrm{CDCl}_{3}\right) \delta=8.11(\mathrm{~m}, 1 \mathrm{H}), 8.38(\mathrm{dd}, 1 \mathrm{H}, J=$ 7.8, $1.5 \mathrm{~Hz}), 7.55-7.62(\mathrm{~m}, 3 \mathrm{H}), 7.36-7.41(\mathrm{~m}, 1 \mathrm{H})$; MS (EI, $\left.150^{\circ} \mathrm{C}\right), \mathrm{m} / \mathrm{e}(\%): 196$ (100), 181 (20), 104 (18), 77 (60), 65 (70), 51 (60); elemental analysis calculated for $\mathrm{C}_{12} \mathrm{H}_{8} \mathrm{~N}_{2} \mathrm{O}_{2}$ : C, 73.46; H, 4.11; N, 14.28\%. Found: C, 73.46; H, 4.43; N, $14.18 \%$.

2-Phenyl- $1 H$-imidazo[4,5-b]pyridine 8 was eluted using $2 \%$ ether-pentane as eluent M.p. $288-290^{\circ} \mathrm{C}$ (lit., ${ }^{19}$ M.p. $\left.291-293^{\circ} \mathrm{C}\right) ;{ }^{1} \mathrm{H}-\mathrm{NMR}$ (600 MHz, DMSO-d 6 )
反 7.24-7.28 (m, 1H), 7.53-7.62 (m, 3H), $8.08(\mathrm{dd}, 1 \mathrm{H}$, $J=7.8,1.5 \mathrm{~Hz}), 8.24-8.26(\mathrm{~d}, 2 \mathrm{H}, J=1.5,2.1 \mathrm{~Hz})$, $8.35(\mathrm{dd}, 1 \mathrm{H}, J=5.1,1.5 \mathrm{~Hz}) ;{ }^{13} \mathrm{C}-\mathrm{NMR}(150 \mathrm{MHz}$, $\left.\mathrm{CDCl}_{3}\right) \delta: 153.6,153.51,149.2,149.0,142.99,136.98$, $130.9,129.75,129.75,127.8,126.98,118.88$; MS (EI, $\left.100^{\circ} \mathrm{C}\right), \mathrm{m} / \mathrm{e}(\%): 195\left(\mathrm{M}^{+} ; 100\right), 169$ (8), 104 (10), 78 (30), 51 (5); elemental analysis calculated for $\mathrm{C}_{12} \mathrm{H}_{9} \mathrm{~N}_{3}$ : C, 73.83; H, 4.65; N, 21.53\% Found: C, 73.78; H, 4.58; $\mathrm{N}, 21.69 \%$.

\subsection{Thermal Fragmentation of \\ $N$ - $\alpha$-Naphthylbenzamide Oxime II}

$\mathrm{N}-\alpha$-Naphthylbenzamide oxime II was heated at 220 $250^{\circ} \mathrm{C}$ under nitrogen atmosphere as discussed before. The pyrolysate was separated into neutral, phenolic and basic components as mentioned previously. The neutral products were separated by fractional distillation under reduced pressure followed by column chromatography to give the following fractions: Benzonitrile $\mathbf{1}$ and benzoic acid $\mathbf{2}$ were identified as mentioned before. Amino compounds were separated into its constituents by fractional distillation under reduced pressure such as $\alpha$-naphthylamine 10, collected B.p. 210$217^{\circ} \mathrm{C} / 6$ Torr; M.p. $47-50^{\circ} \mathrm{C}$. Quantitative separation of the basic fraction was done by column chromatography into the following fractions as $\alpha$-naphthylamine $\mathbf{1 0}$ (in part) was eluted using pet-ether $\left(60-80^{\circ} \mathrm{C}\right)$ as eluent; M.p. $\quad 45-48^{\circ} \mathrm{C}$. $\mathrm{N}$-( $\alpha$-Naphthyl)benzamide 12 was eluted using pet-ether $\left(60-80^{\circ} \mathrm{C}\right)$-benzene $(1: 1 \mathrm{v} / \mathrm{v})$ as eluent; M.p. $164-160^{\circ} \mathrm{C}$ (lit., ${ }^{20}$ M.p. $159-161^{\circ} \mathrm{C}$ ); IR $\left(\mathrm{KBr}, \mathrm{cm}^{-1}\right): 3237,3047,1649,1593,1526,1501 ;{ }^{1} \mathrm{H}-$ NMR $\left(600 \mathrm{MHz}, \mathrm{CDCl}_{3}\right) \delta$ 7.58-7.67 (m, 5H, Ar), 7.80 $(\mathrm{d}, 1 \mathrm{H}, J=7.8 \mathrm{~Hz}), 7.96-7.97(\mathrm{~m}, 3 \mathrm{H}), 8.04(\mathrm{~d}, 2 \mathrm{H}, J=$ $7.0 \mathrm{~Hz}), 8.11(\mathrm{~d}, 1 \mathrm{H}, J=7.0 \mathrm{~Hz}), 8.24(1 \mathrm{H}, \mathrm{br}, \mathrm{NH})$; MS (EI, $150^{\circ} \mathrm{C}$ ), m/e (\%): 247 (28), 144 (5), 115 (18), 105 (100), 77 (48), 51 (10).

2-Phenyl naphtho[1,2-d]oxazole $\mathbf{1 1}$ was eluted using

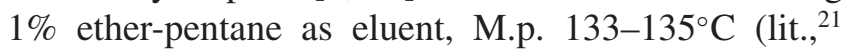
M.p. $130-133^{\circ} \mathrm{C}$; IR $\left(\mathrm{KBr}, \mathrm{cm}^{-1}\right)$ : $1551,1485(\mathrm{C}=\mathrm{N})$, $1238(\mathrm{C}-\mathrm{O}) ;{ }^{1} \mathrm{H}-\mathrm{NMR}\left(600 \mathrm{MHz}, \mathrm{DMSO}-\mathrm{d}_{6}\right) \delta 7.55(\mathrm{~m}$, $2 \mathrm{H}), 7.70(\mathrm{~m}, 3 \mathrm{H}), 8.10(\mathrm{~m}, 2 \mathrm{H}), 8.32(\mathrm{~m}, 4 \mathrm{H}) ;{ }^{13} \mathrm{C}-$ NMR $\left(150 \mathrm{MHz}, \mathrm{DMSO}-\mathrm{d}_{6}\right) \delta 106.5,117.0,123.5$, $124.2,124.8,125.5,126.1,127.7,127.9,128.3,129.3$, $131.1,131.3,132.5,141.4,149.0,164.2$; MS (EI, $\left.100^{\circ} \mathrm{C}\right), \mathrm{m} / \mathrm{e}(\%): 245$ (100), 217 (5), 140 (3), 122 (6), 114 (45), 88 (7); elemental analysis calculated for $\mathrm{C}_{17} \mathrm{H}_{11} \mathrm{NO}$ : C, 83.28; H, 4.52; N, 5.71\%. Found: C, 83.28; H, 4.55; N, 5.74\%.

2-Phenyl-3H-naphtho[2,1-d]imidazole 13 was eluted using $2 \%$ ether-pentane as eluent, M.p. $215-217^{\circ} \mathrm{C}$ (lit., ${ }^{22}$ M.p. $\left.216-218^{\circ} \mathrm{C}\right) ; 1 \mathrm{H}-\mathrm{NMR}(600 \mathrm{MHz}$, DMSO$\left.\mathrm{d}_{6}\right) \delta 7.55(\mathrm{~m}, 2 \mathrm{H}), 7.76(\mathrm{~m}, 3 \mathrm{H}), 8.17(\mathrm{~m}, 2 \mathrm{H}), 8.34$ 
$(\mathrm{m}, 4 \mathrm{H}) ;{ }^{13} \mathrm{C}-\mathrm{NMR}\left(150 \mathrm{MHz}, \mathrm{DMSO}-\mathrm{d}_{6}\right) \delta$ 153.5, $133.3,133.2,132.5,131.0,130.9,129.6,129.4,128.2$, $128.0,126.5$ (2C), 126.0, 125.3 (2C), 124.4, 110.8; MS (EI, $\left.150^{\circ} \mathrm{C}\right), \mathrm{m} / \mathrm{e}(\%): 244$ (100), 140, (20), 121 (33), 114 (18), 77 (5); elemental analysis calculated for $\mathrm{C}_{17} \mathrm{H}_{11} \mathrm{~N}_{2}$ : C, 83.57, H, 4.92; N, 11.47\%. Found. C, 83.45; H, 5.04; N, $11.31 \%$.

\subsection{Thermal fragmentation of \\ $\mathrm{N}$-2-pyridylbenzamidoxime I in tetralin}

The N-2-pyridylbenzamidoxime I (1 g) was placed in a $100 \mathrm{~mL}$ three necked flask with a gas inlet and

Table 1. Thermolysis products of N-Arylbenzamidoximes I and II in \% Yields.

\begin{tabular}{lccc}
\hline Products $^{\mathrm{a}}$ & I & II & I $^{\mathrm{b}}$ \\
\hline Benzonitrile 1 & 2.7 & 4.3 & 3.1 \\
Benzoic acid 2 & 2.1 & 7.5 & 2.5 \\
Arylamines 4, 10 & 2.6 & 13.3 & 5.8 \\
2-Hydroxypyridine 3 & 3.7 & - & 4.5 \\
Anilides 9, 12 & 18.1 & 20.8 & 11.6 \\
Benzoxazoles 5, 11 & 4.3 & 8.3 & 5.2 \\
Benzimidazoles 8, 13 & 52.4 & 38.8 & 40.1 \\
2,4,6-Triphenyl-1,3,5-triazine 7 & 2.8 & - & 1.2 \\
9H-Pyrrolo[2,3-b:4,5-b'] dipyridine 6 & 3.5 & - & 1.8 \\
Other Products 14, 15, 16 & - & - & 23.7 \\
Recovered benzamidoximes I and II & 3.2 & 4.6 & 1.8 \\
\hline
\end{tabular}

a) $\mathrm{NH}_{3}$ was detected by chemical tests; $\mathrm{H}_{2} \mathrm{O}$ as a trace amount was separated with ether and dried drops were identified by dipicrylamine test. ${ }^{34}$

b) Irradiation of $\mathbf{N}$-2-pyridylbenzamidoxime $\mathbf{I}$ in presence of tetralin as radical scavenger.

c) The isolated products of thermolysis of $\mathbf{I}$ in tetralin as 1-hydroxytetralin 14 (11.2\%), $\alpha$-tetralone 15 (7.3\%) and 1,1'-bitetrayl $16(5.2 \%)$. condenser with heated under reflux at boiling anhydrous tetralin $(10 \mathrm{~mL})$ (distillation over lithium aluminum hydride under nitrogen) B.p. ca. $210^{\circ} \mathrm{C}$ for $8 \mathrm{~h}$. The pyrolysate was evaporated in vacuo. The resulting residue was extracted with ether and was evaporated to dryness then subjected to distillation under reduced pressure for separation of lower boiling products such as benzonitrile 1, 2-hydroxypyridine $\mathbf{3}$ and 2-aminopyridine $\mathbf{4}$ as mentioned before, whereas $\alpha$ atetralone 15 was collected at B.p. $113-6^{\circ} \mathrm{C} / 6$ Torr; $\mathrm{n}_{\mathrm{D}}^{20}$ : $1.5679 ; \mathrm{m} / \mathrm{e} 146$ and 1-hydroxytetralin 14 was collected at B.p. $102-5^{\circ} \mathrm{C} / 2$ Torr as pale yellow oil; $\mathrm{n}_{\mathrm{D}}^{20}$ : 1.5638 ; phenyl urethane derivative (ligroin), M.p. and mixed M.p. $120-2^{\circ} \mathrm{C} ; \mathrm{m} / \mathrm{e} 148$. The remaining residue was subjected to further separation into its constituents by column chromatography using ether-pentane as eluent as discussed before. 1,1'-Bitetrayl $\mathbf{1 6}$ was eluted from column chromatography using $2 \%$ mixture of etherpentane, M.p. and mixed M.p. $113^{\circ} \mathrm{C}$; on heating with elemental sulfur gave bis-naphthylene $;{ }^{23} \mathrm{~m} / \mathrm{e} 262$. The results are summarized in table 1 .

\section{Results and Discussion}

The thermolysis of the $\mathrm{N}$-arylbenzamidoxime derivatives I and II described in the present work was done to shed more light on the proposed mechanism of the thermolysis pathways and detection and identification of the different products which sometimes are difficult to be synthesized under normal synthetic procedures.

N-2-Pyridylbenzamidoxime $\mathbf{I}$ on thermolysis at $220-250^{\circ} \mathrm{C}$ for $5 \mathrm{~h}$ under nitrogen atmosphere produced 2-phenyl-1H-imidazo[4,5-b]pyridine 8 and $\mathrm{N}$-(pyridin2-yl) benzamide 9 as the major products (52.4 and $18.11 \%$, respectively), in addition to 2-hydroxypyridine

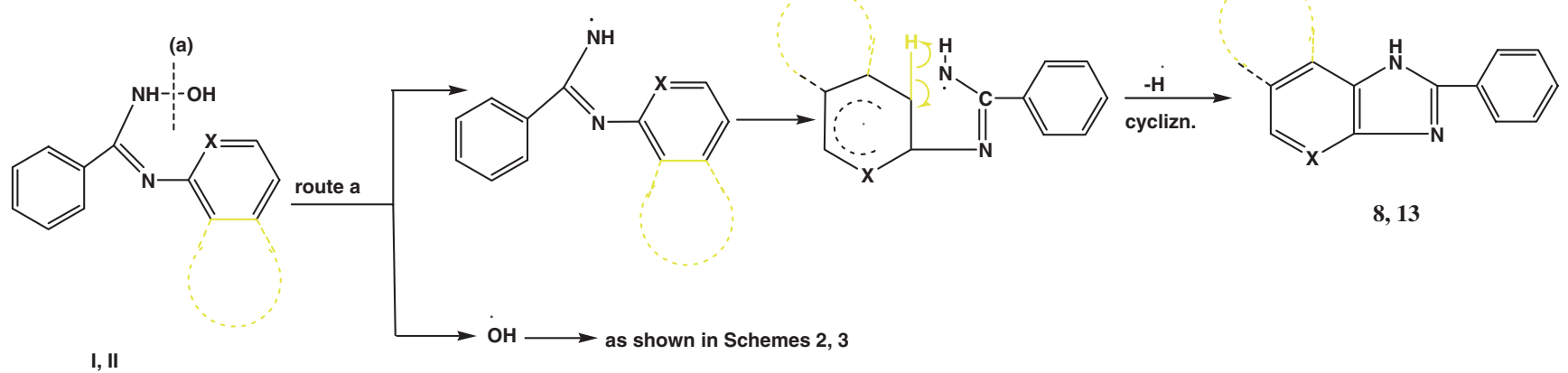

I, II

$$
\begin{aligned}
& \mathrm{I} ; \mathrm{x}=-, \quad \cdots= \\
& \text { II; } \mathrm{X}=\mathrm{N}, \quad \cdots=-\mathrm{C}_{6} \mathrm{H}_{4}
\end{aligned}
$$

Scheme 1. Mechanistic pathways for formation of imidazole derivatives by fragmentation of N-arylbenzamidoximes I and II. 
3, benzonitrile $\mathbf{1}$, benzoic acid 2, 2-aminopyridine $\mathbf{4}$, 2-phenyloxazolo[4,5-b] pyridine 5, $9 H$-pyrrolo[2,3-b: 5,4-b']dipyridine 6 and 2,4,6-triphenyl-1,3,5-triazine 7 as shown in scheme 1. Although some of the products are present in small amounts due to the variable rate of decay of the free radical intermediate, their presence is of great importance for mechanistic interpretation.

The formation of the identified products can be rationalized by a series of reactions shown in scheme 1 , which imply the primary homolysis of the N-O bond (route a) ${ }^{14}$ to form N-2-pyridylbenzamidinyl and hydroxyl radical pairs. The pyridyl benzamidinyl radicals undergo isomerization followed by intramolecular cyclization to give 2-phenyl- $1 H$-imidazo[4,5-b]pyridine $\mathbf{8}$ $\mathrm{m} / \mathrm{e} 195(52.4 \%)^{24}$ as shown in scheme 1 ; whereas, the hydroxyl radicals may be involved in other processes as shown in schemes 2 and 3.

Another competing pathway for the thermolysis of $\mathrm{N}$-2-pyridylbenzamide oxime $\mathbf{I}$ is the homolysis of the $\mathrm{C}-\mathrm{N}$ bond (route $\mathrm{b}$ ) giving N-2-pyridylbenziminyl and hydroxyaminyl free radicals. The benziminyl radicals may couple with hydroxyl radicals (scheme 2, route a), which are readily available in the reaction medium, to form N-(pyridin-2-yl) benzamide 9, m/e 198, which ultimately undergoes extended hydrolysis and decomposes into benzoic acid and 2-pyridaminyl radical. ${ }^{25}$ Moreover, the 2-pyridaminyl radicals may couple with the hydroxylaminyls radical followed by dehydrogenation and extrusion of nitrogen to produce 2-hydroxy pyridine $3 .^{26}$ In addition, the hydroxylaminyl radicals


Scheme 2. Mechanistic pathways for formation of benzoic acid and anilide derivatives by fragmentation of arylbenzamidoximes I and II. 
may abstract hydrogen to form hydroxylamine which subsequently decomposes into ammonia and water ${ }^{27}$ as shown in scheme 2.

Furthermore, the homolysis of the C-N bond (route b), via the tautomeric form of $\mathbf{I}$ as reported by Tiemann et al. ${ }^{28}$ to afford 2-pyridaminyl radicals which may abstract hydrogen to give 2-aminopyridine 4 , whereas the benziminoxyl radicals undergo fragmentation to yield benzonitrile $\mathbf{1}$ and the hydroxyl radical $^{29}$ (scheme 3).

The observed absence of 2-amino-3-hydroxypyridine 17 which may be formed through attack of the hydroxyl radicals on 2-aminopyridine 4 in the reaction medium among the isolated products may be due to its consumption in the formation of the 2-phenyloxazolo[4,5b]pyridine 5, m/e 196, which can be suggested to take place through condensation of benzoic acid 2 with 2amino-3-hydroxypyridine $\mathbf{1 7}$ in the reaction medium followed by elimination of water. ${ }^{30}$

A plausible mechanism for the formation of 2,4,6-triphenyl-1,3,5-triazine 7 (m/e 309) is through cyclotrimerization of benzonitrile $\mathbf{1}$ which is readily available in the reaction medium as reported previously $^{31}$ (scheme 3).

The formation of $9 H$-pyrrolo[2,3-b:5,4-b']dipyridine $6(\mathrm{~m} / \mathrm{e} 169)$ may take place through dimerization of

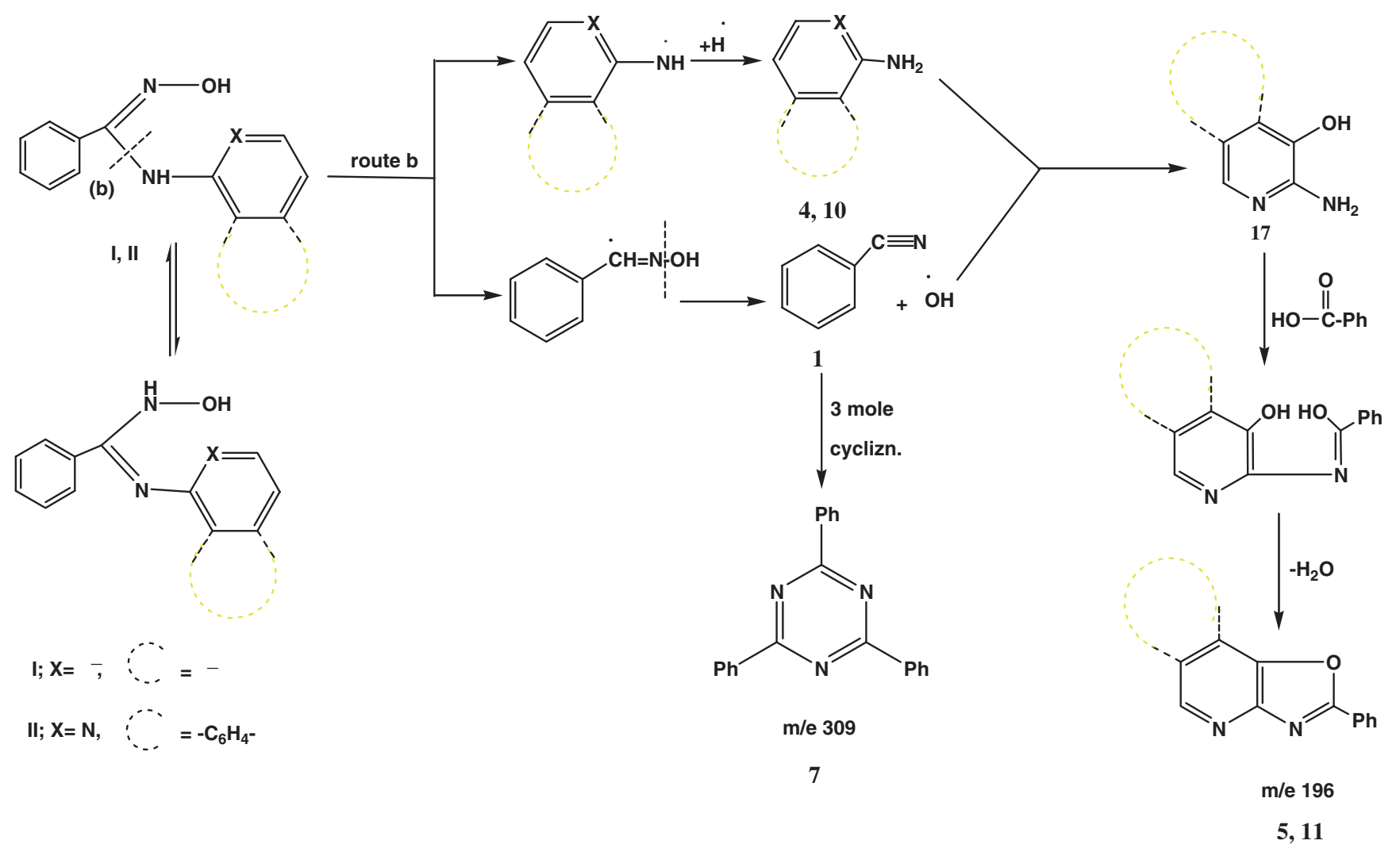

Scheme 3. Mechanistic pathways for formation anilines, triazine and oxazole derivatives by fragmentation of $\mathrm{N}$-arylbenzamidoximes I and II.

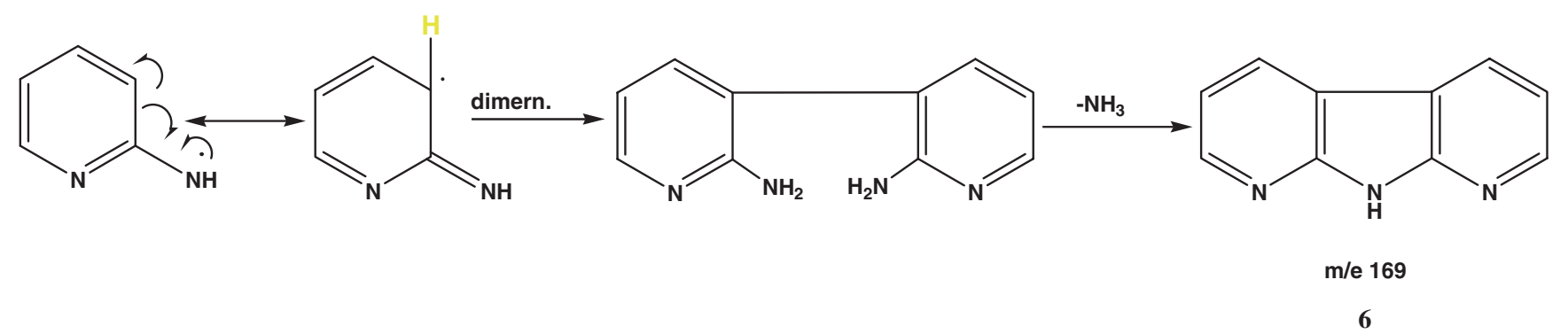

Scheme 4. Mechanistic pathways for formation of $9 H$-pyrrolo[2,3-b: 5,4-b']dipyridine by fragmentation of $\mathrm{N}$-arylbenzamidoximes I and II. 
2-pyridaminyl radicals followed by cyclization and elimination of ammonia ${ }^{17}$ as shown in scheme 4 .

Analogous results were also obtained in the thermolysis $\mathrm{N}-\alpha$-Naphthyl benzamide oxime II under the same conditions leads to the formation of benzoic acid 2, $\alpha$-naphthylamine 10, benzonitrile $1, \mathrm{~N}-(\alpha$-naphthyl)benzamide 12, 2-phenylnaphtho [1,2-d] oxazole $\mathbf{1 1}$ and 2-phenyl-3H-naphtho[2,1-d]imidazole $\mathbf{1 3}$ as the major product $(37.8 \%)$ as shown in schemes $1-3$.

The formation of $\alpha$-naphthylamine $\mathbf{1 0}$ through two routes (scheme 2 , route $a$, and scheme 3 , route b) may correlate for its high yields among the observed products; table 1 . The formation of these products can be explained similar suggested mechanisms as mentioned previously in schemes $1-3$.

Attention has been given to thermal fragmentation of N-2-pyridylbenzamidoxime I under reflux in boiling

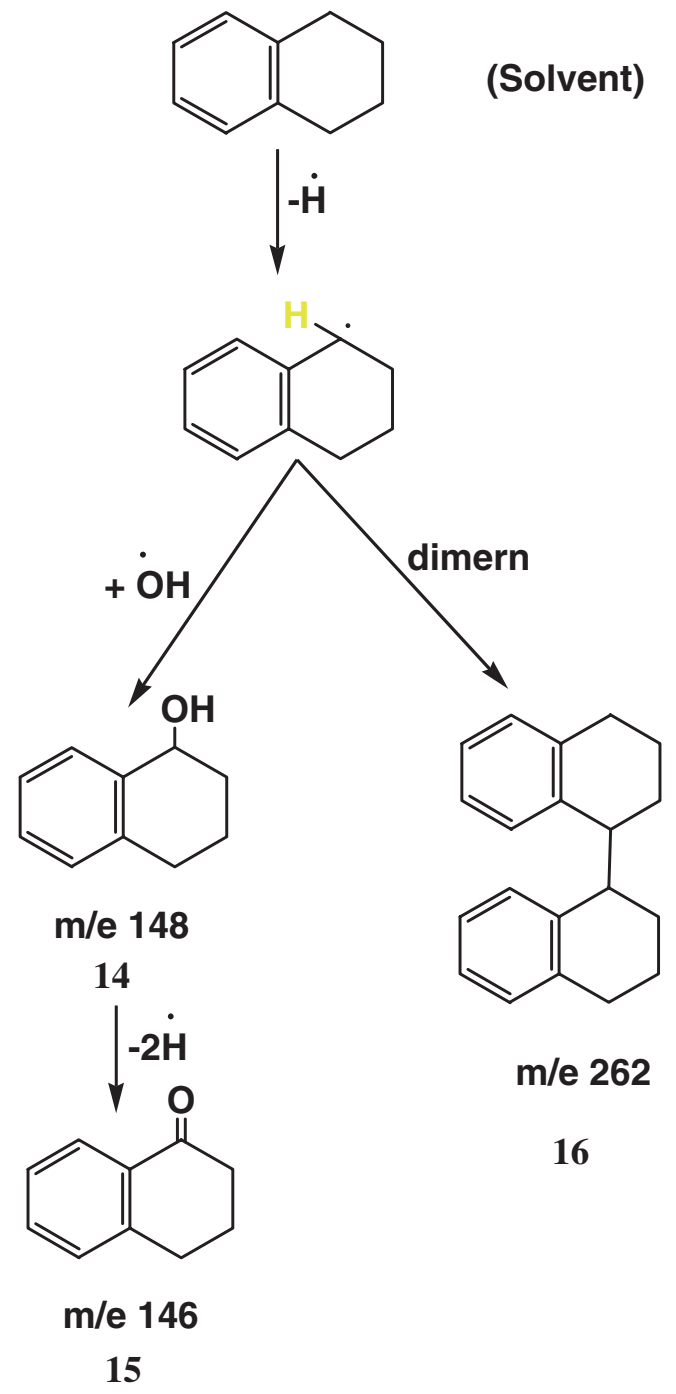

Scheme 5. Mechanistic pathways for formation of 1-hydroxytetralin, $\alpha$-tetralone and 1,1-bitetrayl by fragmentation of N-arylbenzamidoximes I and II in tetralin. anhydrous tetralin $\left(210^{\circ} \mathrm{C}\right)$ formed 1-hydroxytetralin 14, $\alpha$-tetralone $\mathbf{1 5}$ and 1,1'-bitetralyl $\mathbf{1 6}$ as the major products besides the same products as mentioned before, as shown in schemes 1-5.

A possible pathway for the formation 1-hydroxytetralin $14(\mathrm{~m} / \mathrm{e} \mathrm{148)}, \alpha$-tetralone 15 (m/e 146) and 1,1' -bitetrayl $16(\mathrm{~m} / \mathrm{e} \mathrm{262})$ through a process of initial hydrogen abstraction ${ }^{32}$ from the solvent nuclei (tetralin) to form 1-tetrayl radical that interaction with hydroxyl radical which is readily available in the reaction medium followed by oxidative dehydrogenation or the 1-tetrayl radical may undergo dimerization, ${ }^{33}$ respectively, as shown in scheme 5. The results are summarized in table 1 .

\section{Conclusions}

The thermolysis of two N-arylbenzamidoximes I and II was found to be an efficient method for the synthesis of many important organic compound precursors and biologically-active heterocyclic compounds such benzimidazole and benzoxazole derivatives in high yield. The mechanistic pathways for the thermolysis and formation of the products have been proposed on the basis of both analytical and spectroscopic data. Free radical mechanism involving the homolysis of N-O and/or $\mathrm{C}-\mathrm{N}$ bonds was found to be the suitable interpretation of pathways for the formation of the products. Further thermolysis studies and kinetics for another series of organic compounds will be discussed in detail in a forthcoming paper.

\section{Supplementary Information (SI)}

Figures S1-S23 $\left({ }^{1} \mathrm{H}-\mathrm{NMR},{ }^{13} \mathrm{C}\right.$ NMR, Mass, GC data) are available as Supplementary Information for this paper available at www.ias.ac.in/chemsci.

\section{Acknowledgments}

The authors are highly grateful to Umm-Al-Qura University, Saudi Arabia for financial support for this work.

\section{References}

1. Gaber A M, Mauthen H A and Taib L A 2014 In Synthetic applications of the thermolysis of benzamidoxime derivatives (Germany: Lambert Publishing Services) ch. 5 p. 64

2. Eloy F and Lenaers R 1962 Chem. Rev. 62166

3. Trofimov B A, Schmidt E Y, Vasil'tsov A M, Mikhaleva A, Zaitsev A B, Morozova L V, Gorshkov A G, Henkelman J and Arndt J-D 2001 Synthesis 16 2427

4. Moustafa A H 2003 Synthesis 837 
5. Gaber A M and McNab H 2009 J. Anal. Appl. Pyrolysis 86369

6. Gaber A M, Al-Ahmadi A A and Baryyan A O $2008 \mathrm{~J}$. Anal. Appl. Pyrolysis $\mathbf{8 2} 110$

7. Gaber A M, Muathen H A and Taib L A 2011 J. Anal. Appl. Pyrolysis 91119

8. Gaber A M, Muathen H A and Taib L A 2012 J. Anal. Appl. Pyrolysis $\mathbf{9 3} 14$

9. Gaber A M, Ahmed S A, Khairou K S and Taib L A 2014 J. Chin. Chem. Soc. 611147

10. Srivastava R M, Lima A D, Viana O S, Silva M J C, Catanho M T J A and de Morais J O F 2003 Bioorg. Med. Chem. 111821

11. Lamband I D and White A C 1939 J. Chem. Soc. 1253

12. (a) Hall J E, Kerrigan J E, Ramachandran K, Bender B C, Stanko J P, Jones S K, Patrick D A and Tidwell R R 1998 Antimicrob. Agents Chemother. 42 666; (b) Eva B, Debora R, Ralf-Rainer M, Florian B, Anne-Marie M, Philipp K, Ulrich G, Antje H and Bernd C 2015 ChemMedChem. 10360

13. Partridge M W and Turner H A 1958 J. Chem. Soc. 2086

14. Weast R C 1981 In CRC Handbook of Chemistry and Physics 62 ${ }^{\text {nd }}$ Ed. (Boca Raton: CRC Press) p. 193

15. Jozwiak A, Brzezinski J, Plotka M, Szczesniak A, Malinowsbi Z and Epsztajn J 2004 Eur. J. Org. Chem. 3254

16. Zhaoxiang D, Werfeng Q, Weijia L and Yadong L 2004 Chin. Sci. Bull. 49127

17. Clark V M, Cox A and Herbent E J 1968 J. Chem. Soc. 831
18. Fraser J and Tittensor E 1957 J. Chem. Soc. 4625

19. Kale R P, Shaikh M U, Jadhav G R and Gill C H 2009 Tetrahedron Lett. $\mathbf{5 0} 1780$

20. Chaysripongkul S, Pluempanupat W, Jang D O and Chavasiri W 2009 Bull. Korean Chem. Soc. 302066

21. Astolfi P, Corloni P, Castagna R, Greci L, Rizzolib C and Stipaa P 2004 J. Heterocyclic Chem. 41971

22. Perry R J and Wilson B D 1993 J. Org. Chem. 587016

23. von Braun J and Kirschbaum G 1921 Chem. Ber. 54597

24. Libhanova N V, Veloz M A, Hopfl H, Mation D J, Reyas-Cruz V E, Olivares O and Palou R M 2007 J. Heterocyclic Chem. 44145

25. Gaber A M and Nahas N A 2009 Afinidad 539 252

26. Gaber A M and Mohamed S K 1998 J. Chin. Chem. Soc. 45767

27. Betts J and Back R A 1965 Can. J. Chem. 432678

28. (a) Tiemann E and Kruger P 1884 Chem. Ber. 17 1685; (b) Exner O and Jehlicka V 1974 J. Chem. Soc. Perkin II 567

29. Gaber A M and Khairou K S 2011 Monatsh. Chem. 142 1021

30. Garnier E, Blanchard S, Rodriguez I, Jary C, Leger J-M and Caubere P 2003 Synlett 2033

31. Koutentis P A and Mirallai S 2010 Tetrahedron 665134

32. Gaber A M 1998 J. Chem. Res. 288

33. Gaber A M, Muathen H A and Taib L A 2013 J. Chem. Pharm. Res. 5303

34. Feigl F 1960 In Spot tests in organic analysis (Amsterdam: Elsevier) pp. 96-120 